\title{
Acardiac fetus: a challenge to pathologists, obstetricians and neonatologists
}

\author{
Cristiane Rúbia Ferreira ${ }^{a}$, Angélica Braz Simões ${ }^{a}$, Virgínia Spínola Quintal ${ }^{b}$ \\ Maria Cláudia Nogueira Zerbinia
}

Ferreira CR, Simões AB, Quintal VS, Zerbini MCN. Acardiac fetus: a challenge to pathologists, obstetricians and neonatologists. Autopsy Case Rep [Internet]. 2011;1(1):13-9.

\begin{abstract}
Acardius is one of the most severe human malformations, a rare complication present only in monozygotic and monochorionic multiple pregnancies. In this disorder, the major defect is the lack of well-defined cardiac structure in acardiac fetus, whose irrigation is maintained through placental vascular anastomoses with the normal fetus, called fetal donor, thereby establishing a reverse arterial perfusion in the umbilical cord of the acardiac twin (TRAP sequence). The poor circulation leads to a state of hypoxia in the early stages of fetal development, causing structural abnormalities, with different phenotypes, which are classified as: Acardius acephalus, anceps, and acormus amorphus. We relate a case of an acardiac anceps fetus that interestingly was reported by the physicians to present spasmodic movements just after the delivery. Due to severe malformations observed in an acardiac twin by the time of delivery, it is likely that many cases go unnoticed or misdiagnosed. The pathological findings are briefly reviewed to provide an adequate post mortem diagnosis of acardiac fetus and placental examination.
\end{abstract}

Keywords: Fetal heart/abnormalities; Fetus/abnormalities; Disease in twins/physiopathology, Heart defects congenital/pathology; Fetofetal transfusion/complications.

\footnotetext{
${ }^{a}$ Anatomic Pathology Service - Hospital Universitário, Universidade de São Paulo, São Paulo/SP - Brazil.

b Department of Pediatric Clinic - Hospital Universitário, Universidade de São Paulo, São Paulo/SP - Brazil.
} 


\section{INTRODUÇÃO}

The acardiac fetus is a rare congenital malformation, first described by Benedetti ${ }^{1}$ in 1533 , observed in monochorionic multiple pregnancies and characterized by twin reversed arterial perfusion (TRAP sequence). ${ }^{2}$ It is a rare occurrence with an incidence of $1 / 35,000$ pregnancies, complicating about $1 \%$ of monozygotic multiple pregnancies. ${ }^{3,4}$

The vascular anastomoses between 2 fetuses are present in almost all monochorionic multiple pregnancies, which can occur superficially on the surface of the chorion and deeply within the villous tissue of the placenta. Usually those vascular anastomoses are inconsequential, but when demanded by hemodynamically significant flow they can lead to shunt development. ${ }^{5}$

In the TRAP sequence, the extreme end of this pathologic vascular anastomoses on the monochorionic placenta, the inadequate perfusion during early steps of the embryogenesis results in one fetus, called recipient, becoming dependent on a vascular shunt from its co-twin, designated pump or donor, with severe and lethal malformation resulting of the low flow and hypoxic blood circulation. ${ }^{2}$ Considering the pathogenesis issue of the TRAP sequence in the embryogenesis, there is a spectrum of malformation including: acardius acephalus, acardius anceps, acardius acormus and acardius amorphous. $^{1,6}$

We relate a case of an acardiac anceps fetus that interestingly was reported by the physicians to have presented spasmodic movements just after the delivery. The pathological findings are briefly reviewed to provide an adequate pos-mortem diagnosis of acardiac fetus and placental examination.

\section{CASE REPORT}

A 27-year-old, gravida 3, para 2, woman was referred to us at $344 / 7$ weeks of twin pregnancy. Ultrasound examination indicated a twin reversed arterial perfusion (TRAP) sequence, with a normal vital female fetus (twin 1) and an acardiac fetus (twin 2). A cesarean section was performed. While twin 1 was a healthy liveborn female infant without external malformations, twin 2 was a hydropic and dysmorphic indeterminate sex fetus with 1,380 g weight (Figure 1A).

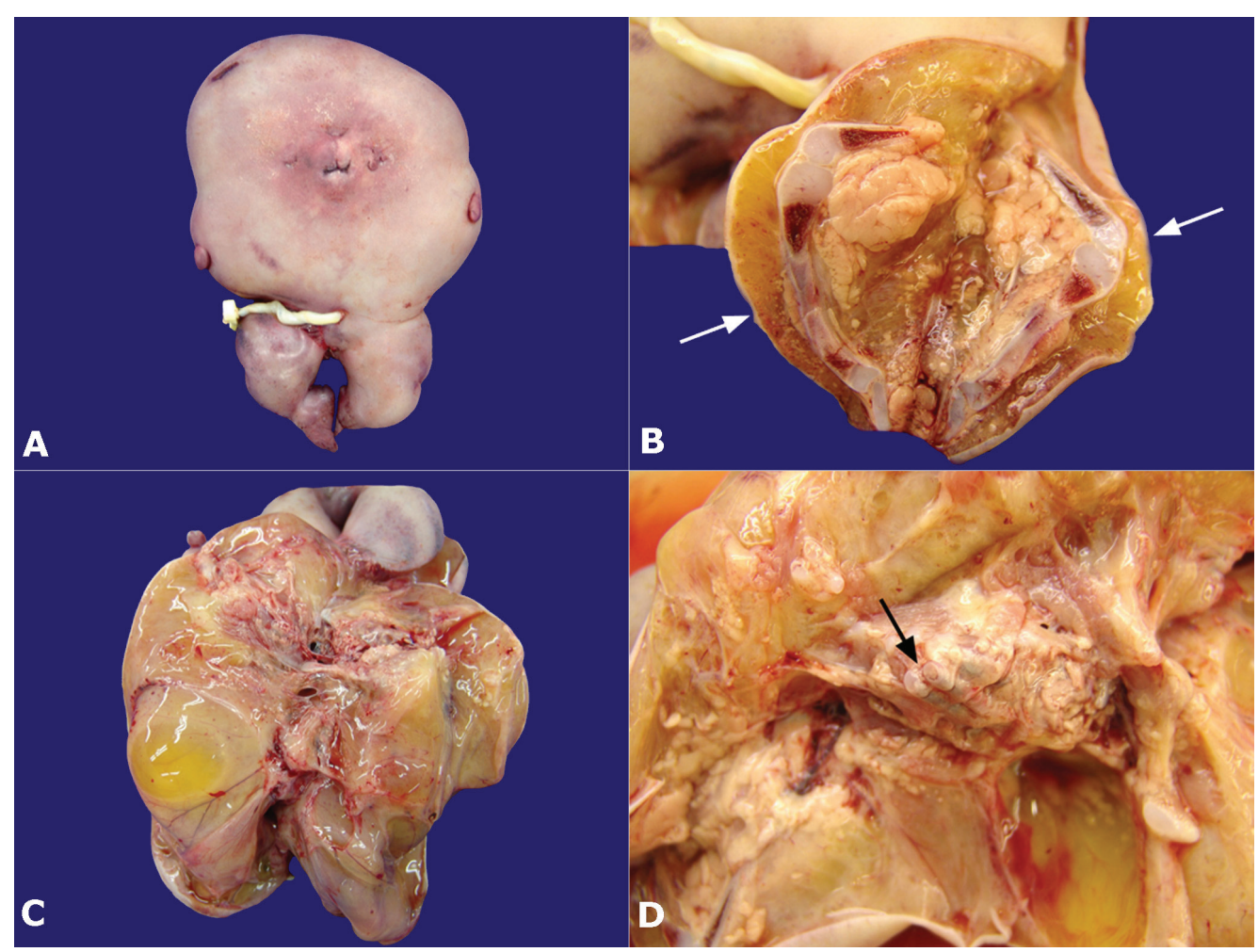

Figure 1- A- Panoramic picture of the acardiac anceps fetus with a rudimentary face and no clear demarcation between the head and trunk. The umbilical cord is attached at the abdominal wall. B- Section of the lower limb showing the femur and tibia. C-Coronal view showing edematous subcutaneous tissue surrounding a bone structure that represents the axis. D- Rib (arrow). 
Interestingly, despite the lack of evidence of breath or beating of the heart, it was observed unquestionable spasmodic movement in twin 2, raising the differential diagnosis between acardiac fetus previously diagnosed by ultrasound and remote possibility of early neonatal death in this extremely malformed fetus.

On gross examination, the twin 2 was extremely malformed with no clearly discernible neck or demarcation between the head and trunk. There was an umbilical cord attached to the abdominal wall. A rudimentary face was seen, with no separation of the eyelids, undeveloped nose and a small mouth cavity with a small tongue. The upper limbs were rudimentary. Two lower limbs had feet with oligodactyly, with two metatarsals and two digits on each side (Figure 1A). The anus was absent. In the genital region there was a cutaneous bud, with no discernible genital organs. The X-ray demonstrated skeletal axle and lower limbs (Figure 2).

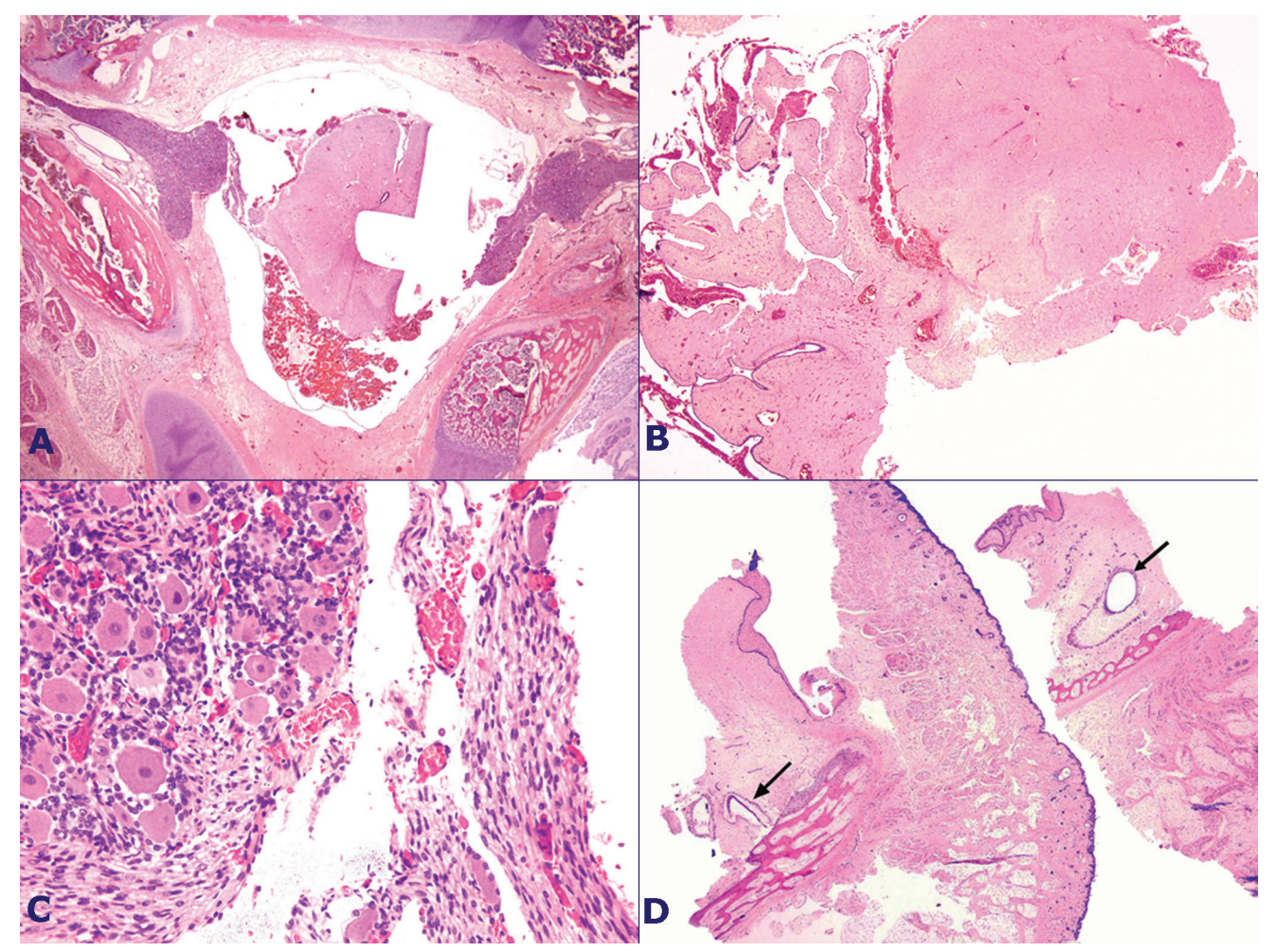

Figure 2- X-ray showing skeletal axle - AP (A) and lateral (B), with presence of small cranium, vertebral column and lower limbs.

Internal examination revealed thickened edematous subcutaneous tissue and bone structures, small cranium with vertebral column and ribs representing an axle (Figures 1C and 1D). The neurocranium was small, globular, containing rudimentary brain. Spinal column was quite normal, as well as vertebras, clavicles and ribs. The body cavity inside the ribs showed absence of larynx, esophagus, trachea, heart and aortic arch, lungs, diaphragm, liver, pancreas, spleen, and kidneys. There were many intestinal loops with blind ends, representing the stomach, small and large bowel, and one adrenal gland. In the pelvic soft tis- sue there was a rudimentary urinary bladder. Bones of the upper extremities were absent, while the femurs and tibias were well developed in the lower extremities (Figure 1B).

Light microscopic examination revealed ectasia of the lymphatic vessels in the subcutaneous and soft tissue along intestinal loops, with no discernible cardiac muscle. Brain tissue was rudimentary, but a well organized neural tissue characterized by neural branching with ganglion cells representing paraspinal ganglia was observed in spinal cord (Figure 3). 


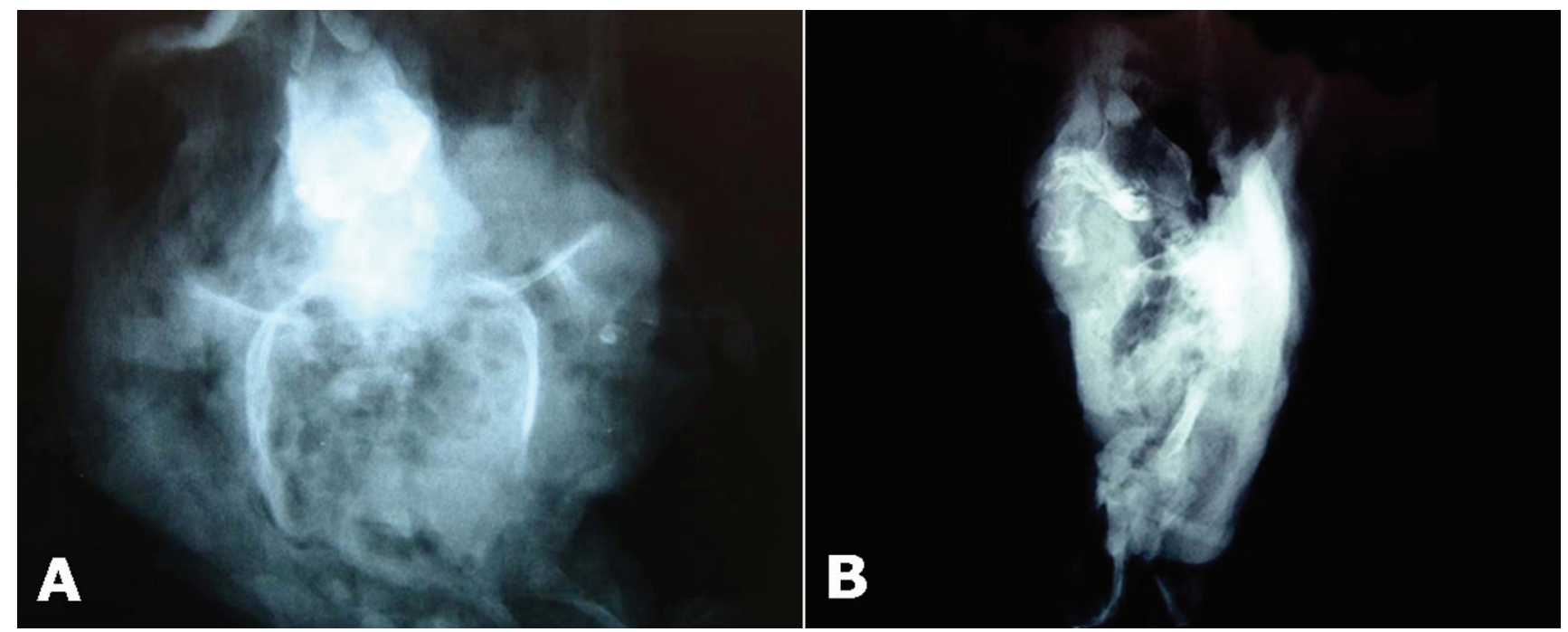

Figure 3- A- Vertebral column and spinal cord (HE-25x). B- Rudimentary brain tissue (HE-25x). C- Neural paravertebral ganglion (HE-200x). D- Rudimentary eyeball (HE-25x).

The twin placenta was monochorionic diamnionic measuring $15.0 \times 13.0 \times 2.0 \mathrm{~cm}$ and weighing $350.0 \mathrm{~g}$. Umbilical cord of the first twin $\left(\mathrm{n}^{\circ} 1\right)$ presented marginal insertion, measured $32.0 \mathrm{~cm}$ in length and $2.5 \mathrm{~cm}$ in diameter and contained 03 vessels. Umbilical cord of the second twin $\left(n^{\circ} 2\right)$, the acardiac fetus, was forked, with marginal insertion, and measured $6.5 \mathrm{~cm}$ in length with diameters ranging from 0.5 to $1.0 \mathrm{~cm}$. Placental fetal surface had prominent vessels which branched off from each of the umbilical cords toward the opposite cord, being more prominent in the territory of the first twin toward the second twin, the acardiac one, suggestive of vascular anastomosis. Placental maternal surface featured cyanosis, edema, and laceration near the area of the second twin. The serial sections of umbilical cord of the second twin $\left(n^{\circ} 2\right)$ revealed single umbilical artery along the distal two-thirds, associated with hypoplasia of the second artery that was identified in the proximal segment (Figure 4).

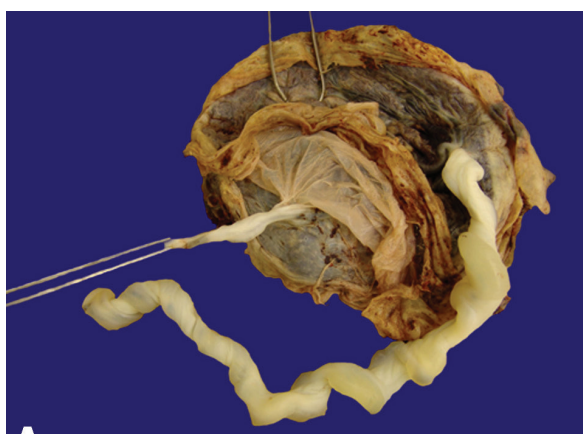

A

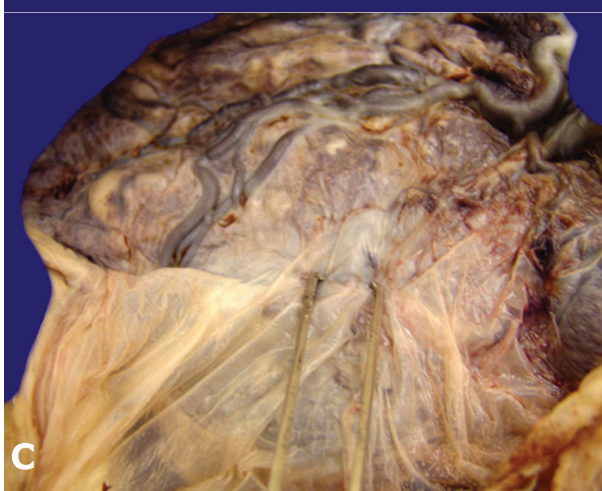

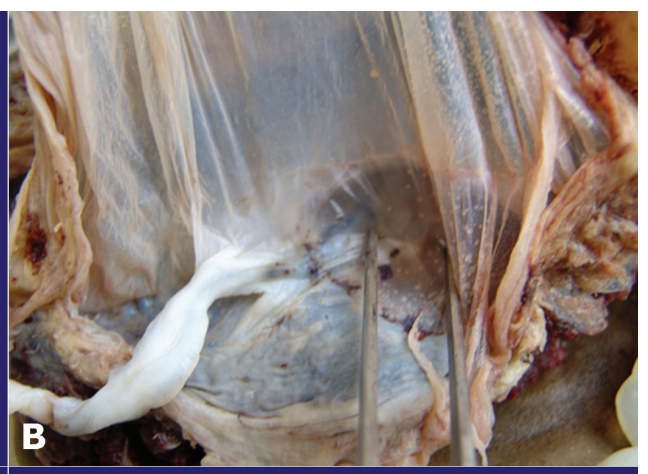

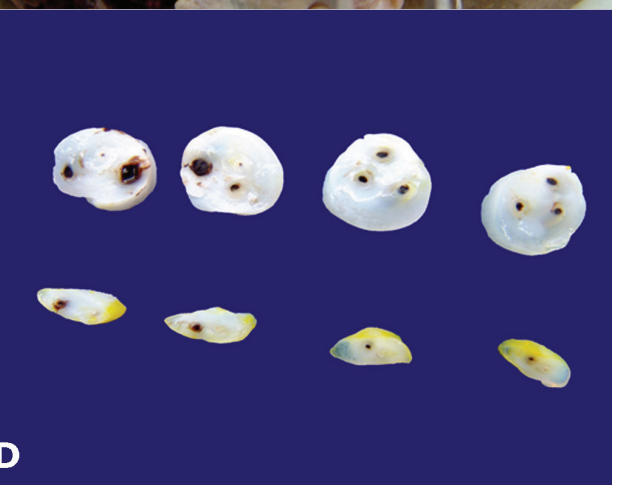

Figure 4- A- Monochorionic diamnionic twin placenta. B- Umbilical cord and presence of prominent vessels within the territory of twin 2 (acardiac fetus). C- Presence of prominent vessels within the territory of twin 1 (normal fetus), suggestive of superficial vascular anastomosis. D- Above, the umbilical cord of the twin 1 with 3 vessels, and below, the umbilical cord of the twin 2 (acardiac fetus) with single umbilical artery. 
It was also observed the presence of amnion nodosum in the amniotic surface and villous maturation dyssynchrony with intense congestion of tertiary villi on the histology sections of the second twin region (Figure 5).

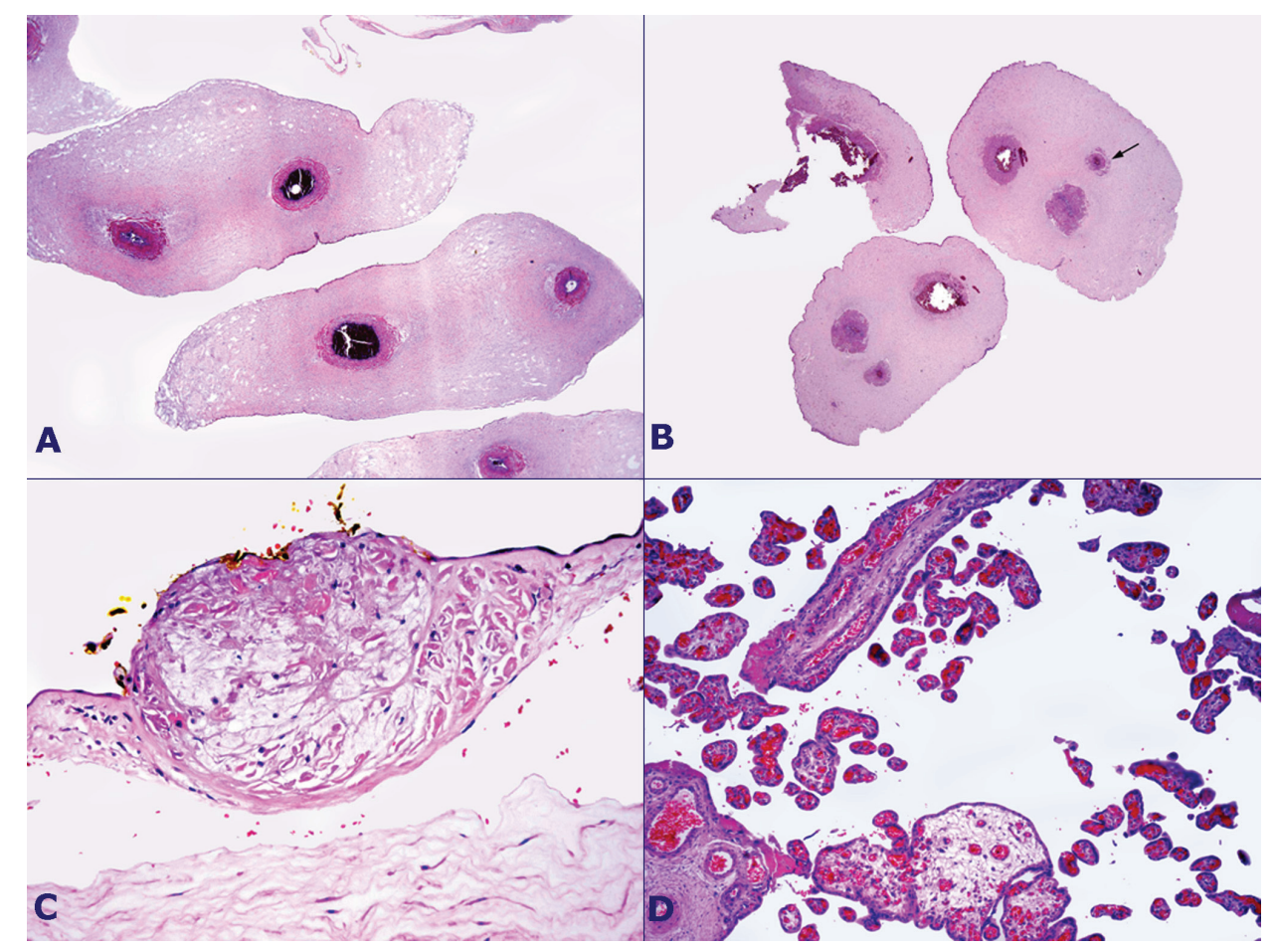

Figure 5- Pathological findings of the placenta in the territory of the twin 2 (Acardiac fetus). A- Histological section of the umbilical cord showing single umbilical artery along the distal two-thirds. B- Histological section of the umbilical cord showing hypoplasia of the second umbilical artery along the proximal one-third. C- Amnion nodosum in the amnion. DHypoplasia of secondary villous and tertiary villous congestion (rarefaction and dyssynchrony)

\section{DISCUSSION}

Despite the severe malformations that are not compatible with extra uterine life, we report a case of an acardiac anceps twin displaying spasmodic movement just after the delivery. Concerning the concepts of the uterine human life, an acardiac twin is an alive extremely malformed fetus, with lethal malformation like acardia and usually also acephaly, which is kept alive by its normal co-twin (the pump twin) through vascular placental anastomosis. ${ }^{6}$

According to $\mathrm{WHO}^{7}$ criteria, live birth is the complete expulsion or extraction from its mother of a product of conception, irrespective of the duration of pregnancy, which, after such separation, breathes or shows any other evidence of life, such as beating of the heart, pulsation of the umbilical cord, or definite movement of voluntary muscle, whether or not the umbilical cord has been cut or the placenta is attached. However, the movements of voluntary muscle depend not only on the integrity of skeletal muscle and spinal cord but also of the central nervous system, such as the cerebral cortex and cerebellum, which play an im- portant role in motor function. ${ }^{8}$

Despite the presence of vertebral column with spinal cord and paraspinal ganglia relatively preserved, the cerebral parenchyma in this acardiac fetus was very rudimentary. Apart from that, there was no well developed skeletal muscle tissue in the lower limbs or trunk. So surely the spasmodic movements reported by the physicians in this case could not represent the movement of voluntary muscles, but reflex movements that do not fit the definition of life proposed by $\mathrm{WHO} .{ }^{7}$ Although an acardiac twin is a stillbirth, in some cases, reflex movements of the acardiac fetus may be seen by sonography ${ }^{5,9}$ suggesting that they are still alive intra utero, but no information exists on the accuracy of those movements, mainly in monoamniotic twins, when the acardiac fetus is driven through the amniotic cavity by its normal co-twin. ${ }^{10}$

Due to the lack of communication between the lymphatic and vascular systems, the acardiac 
twin frequently develops severe subcutaneous edema and cystic hygromas, which can significantly increase the size of the fetus and distort the already abnormal anatomy. ${ }^{5}$

Regarding to the pathogenesis, most acardiac twin are chromosomally normal ${ }^{11}$, with chromosomal abnormalities in about $33 \%$ of cases and only in monozygotic identical twins ${ }^{12,13}$, strengthening the theory of the teratology of the low oxygenated blood in embryogenesis, due to reversed arterial perfusion, the TRAP sequence. ${ }^{2}$ Two hypotheses are accepted. The first hypothesis supposes that there is a primary defect in the development of the heart and that the acardiac twin only survives as a result of the compensatory anastomoses that develop. ${ }^{14}$ The second hypothesis believes that acardiac twin begins life as a normal fetus, and that the reversal in the circulatory blood flow in early steps of the embryogenesis results in an impediment of the development or in atrophy of the heart and other organs. ${ }^{15}$

There was no definite sexual organ in our acardiac twin, but its normal co-twin was female, according to the literature, where the majority of acardiac twins and their normal plump twin are female. ${ }^{16}$ There are variable grades of developmental disruption in the acardiac fetus, and based on morphology they are separated into four groups ${ }^{1}$ :

1. Acardius acephalus, with a well-developed pelvis and lower limbs, but headless, and usually without thoracic organs or arms. This is the most common form.

2. Acardius anceps, is the most developed form, with a partially developed head, brain tissues and facial structures. The body and extremities are also welldeveloped, corresponding to the case here reported.

3. Acardius acormus, is the rarest type, where there is only the head without the rest of the body.

4. Acardius amorphous, that is represented by a shapeless mass containing no recognizable human organs, but usually with some form of axial structure.

Of note, it is important not only to recognize the morphologic spectrum anomalies in the acardiac fetus, but also rule out the differential diagnosis of a teratoma from the placental surface or umbilical cord. Prenatally, two ultrasound criteria can be used for diagnosis: first is the presence of a separate, even rudimentary, umbilical cord in the acardiac fetus. Second is the presence of some evidence of body organization or axial structure, whereas the tissues in teratomas are completely disorganized. Postpartum, there is an additional criterion: the acardiac fetus is always covered by normal skin. 6,17,18

The placenta in pregnancies complicated by acardiac anomaly has not been studied in great detail in the literature. In one pathological series of 30 cases, one-third had a monochorionic-monoamniotic placenta and two-thirds had monochorionic-diamniotic placenta $^{17}$, as was this case. All placentas have a similar pattern consisting of the presence of two anatomoses, one artery-to-artery and one vein-to-vein, connecting the circulation between the acardiac and the pump twins. Those anastomoses are usually on the placental surface and allow blood flow between the acardiac twin's umbilical cord and the major arterial and venous branches of the cord of the pump twin. The acardiac twin acts as a parasite that is hemodynamically dependent upon the pump twin. Consequently, as a result of this vascular connection, acardiac twins always lack functional placental tissue ${ }^{6}$, as was demonstrated by the acardiac twin area in this placenta with villous maturation dyssynchrony and hypoplasia of tertiary villous. We also documented a single umbilical artery, associated with hypoplasia of the second artery that was identified in the proximal length of the umbilical cord of the acardiac twin. The finding of a single umbilical artery was described in about $66 \%$ of the cases. ${ }^{5}$

Due to severe malformations observed in an acardiac twin by the time of delivery, it is likely that many cases are misdiagnosed by the physicians. Many of these cases could be diagnosed at autopsy. This case illustrates the importance of recognizing that the acardiac fetus is a stillborn, nonviable fetus, and also to perform the correct diagnosis of the placenta, that plays an important role in the pathophysiology of this anomaly.

\section{ACKNOWLEDGMENTS}

We are grateful to Rosa Maria C. Zanardi and Júlio César Barbosa de Santana, who kindly helped us with the documentation of the images presented in this case. 


\section{REFERENCES}

1. Napolitani FD, Schreiber I. The acardiac monster: a review of the world literature and presentation of 2 cases. Am J Obstet Gynecol. 1960;80:582-9.

2. Van Allen MI, Smith DW, Sheppard TH. Twin reversed arterial perfusion (TRAP) sequence: a study of 14 twin pregnancies with acardius. Semin Perinatol. 1983;7:285-93.

3. Gillim DL, Hendricks $\mathrm{CH}$. Holoacardiacus: review of the literature and a case report. Obstet Gynecol. 1953;2:647-53.

4. James WH. A note on the epidemiology of acardiac monsters. Teratology. 1977;16:211-6.

5. Malhotra N, Sinha A, Deka Deepika, Roy KK. Twin reversed arterial perfusion: Report of four cases. J Clin Ultrasound. 2004;32:411-4.

6. Wong AE, Sepulveda W. Acardiac anomaly: current issues in prenatal assessment and treatment. Prenat Diagn. 2005;25:796-806.

7. World Health Organization. Neonatal and perinatal mortality: country, regional and global estimates. Geneva: World Health Organization; 2006 [cited 2011 Feb. 19]. Available from: http://www.searo.who.int/LinkFiles/Making_Pregnancy_Safer_Neonatal_Perinatal_06.pdf.

8. Machado ABM, Campos GB. Neuroanatomia funcional. 2a ed. rev. ampl. São Paulo: Atheneu; 2001. 363p.
9. Pezzati M. Acardiac twins. Two case reports. J Perinatal Med. 1997;25:119.

10. Fusi L, Fisk N, Talbert D, et al. When does death occur in an acardiac twin? Ultrasound diagnostic difficulties. J Perinat Med. 1990;18:223-7.

11. Blaicher W, Repa C, Schaller A. Acardiac twin pregnancy: associated with trisomy 2. Hum Reprod. 2000;15:474-5.

12. Hanafy A, Peterson CM. Twin reversed arterial perfusion (TRAP) sequence: case reports and review of the literature. Aust NZ J Obstet Gynaecol. 1997;37:187.

13. Fisk NM, Ware M, Stanier P, Moore G, Bennett P. Molecular genetic etiology of twin reversed arterial perfusion sequence. Am J Obstet Gynecol. 1996;174:891-4.

14. Severn $C B$, Holyoke EA. Human acardiac anomalies. Am J Obstet Gynecol. 1973;116:358-65.

15. Coulam CB, Wright G. First trimester diagnosis of acardiac twins. Early Pregnancy. 2000;4:261-70.

16. Blenc AM, Gomez JA, Collins D, Lee MW. Pathologic quiz case. Arch Pathol Lab Med. 1999;123:974-6.

17. Benirschke K, Kaufmann P. Pathology of the Human Placenta. 2nd ed. Springer: New York; 1995:702-10.

18. Spencer R. Parasitic conjoined twins: External, internal (fetuses in fetu and teratomas), and detached (acardiacs). Clin Anat. 2001;14:428-44.

\section{Conflict of interest: None}

Submitted on: $21^{\text {th }}$ February 2011

Accept on: 11th March 2011

Correspondence: Serviço de Anatomia Patológica

Av. Prof. Lineu Prestes, 2565 - Cidade Universitária - São Paulo - SP - Brazil

CEP 05508-900 - Phone: +55.011. 3091-9384.

E-mail: crisrf@hu.usp.br 